\title{
The writing skills course as an introduction to critical practice for larger business undergraduate classes
}

\author{
John G Cullen, National University of Ireland Maynooth \\ DOI:10.3794/ijme.93.352
}

Received: January 2011

Revised: June 2011, August 2011

Accepted: August 2011

\begin{abstract}
Calls for greater levels of critical thought in business and management education increased in the wake of the global financial crisis. Many business educators articulated a need to develop students who engage with theory at the deepest level in order to cultivate more socially engaged managers and management thinkers. These calls surfaced at a time when organisations voiced concerns about the quality of the basic literacy and numeracy skills of graduates. It is often difficult to introduce students to critical practice at the undergraduate level due to larger class sizes, with the result that deeper theoretical engagement is often postponed until postgraduate stages of business education. This paper discusses the findings from an action research project conducted on a critical writing skills project which aimed to introduce a group of 95 first-year business students to the concept of critical practice through their written assignments. The research unearthed some opportunities, challenges and possible pitfalls associated with deploying a critical writing skills module paper, with the aim of informing practice and signposting future research needs.

Keywords: writing skills; critical thinking; action research; larger classes
\end{abstract}

\section{Introduction}

Following the economic downturn at the start of the millennium, some of the major figures in mainstream management theory (Bennis \& O'Toole, 2005; Ghoshal, 2005; Mintzberg, 2004) called for a root-and-branch revision of the principles taught in business schools. It was alleged that an emphasis on transaction-cost economics had produced a form of graduate who was entirely self-interested, amoral and disconnected from their communities and society in general. These polemics advocated a form of management education that was respectful of the context in which management happened, and sought a form of business education which prioritised the social over the economic. In the aftermath of the recent global economic downturn these calls again issued from business schools. However, this time the calls were for business graduates who were not only well versed in management theory, but were also capable of being critical of the concepts which they encounter (Martin, 2010; Newman, 2010).

A significant structural aspect of critical management education is often overlooked by the growing number of business faculty who advocate critical practice in business education; larger class sizes have become more prevalent. Increased student volume makes it difficult to communicate the importance of critical thinking. This has several implications for the management educator in terms of student engagement and how we assess the development of critical practice amongst students.

\section{Problems associated with introducing the "critical" into undergraduate manaement education}

Mingers (2000) stated that:

The academic literature is full of theoretical debate, empirical studies and practical guidance for effective management. It lacks, however much by way of considered reflection about the practice of management education itself. (p. 219)

The existence of multiple understandings of what critical thinking is, and how it can be taught and assessed, is not an issue which is specific to management education (Abrami et al., 2008). The field of critical management studies has grown slowly within European business schools since the mid-1990s (Grey \& Willmott, 2005), but attempts to encourage critical reflexivity in management and business education have usually been attempted in relation to postgraduate researchers (Hagen, Miller, \& Johnson, 2003; Vince, 2010) or experienced executives (Cunliffe, 2002; Raelin, 2007). As the critical pedagogy literature tends to be directed at post-experience adult learners (Dehler, 2009), the encouragement of a critically reflexive

John $G$ Cullen lectures in organisational behaviour, leadership, management and business ethics at the Department of Management, School of Business at the National University of Ireland Maynooth. He is interested in critical approaches to understanding how management is learned and practiced in organisational settings. 
practice can prove problematic when applied to traditional undergraduate scenarios. The sources of this problem are manifold.

Over the past few decades, higher education has become available around the over the world to a degree unimaginable to earlier generations. Once the exclusive preserve of elites, the "massification" of higher education has provided opportunities to an ever-widening group of youth across OECD countries. (Usher \& Cervenan, 2005, p. 2)

These high levels of participation in undergraduate higher education increased dramatically as a result of the severity of the international recession (Flynn, 2010; Williams \& Shepherd, 2010). At the same time, the resources available to higher level institutions, most of which are in receipt of public subsidy (Ferlie, McGivern, \& De Moraes, 2010), have been curtailed as a result of the austerity measures introduced in many countries. Such cutbacks and recruitment moratoria mean that many management education professionals who teach undergraduate students grapple with increased class sizes which further exacerbate the process of encouraging deep, critical thinking amongst students. The difficulty is that deep critical learning and engagement is what is needed at this juncture, to help managers and organisations address the pressing social, economic and environmental consequences that we face globally.

Irregardless of these larger structural problems, the application of critical management pedagogy in the business classroom has not been unproblematic and student evaluations of such modules tend to be mixed at best. Mingers (2000) reported positive student evaluations for a critical management studies course at Warwick University, whilst pointing out that it was a relatively unpopular elective choice amongst the student cohort. More importantly, he noted "that virtually all the students failed to be genuinely critical. They simply accepted the course objectives as given and then reviewed the delivery of the course" (p. 233). This echoes Valentin's (2003) warning that "the danger that in seeking to make sense of this multidisciplinary complexity of understandings, students will be tempted to take on board the received wisdoms of 'critical' authorities without engaging with the debates themselves" (pp. 7-8).

Many undergraduate students become accustomed to learning in large group settings and often experience confusion when asked to consider these same structures. Teachers who attempt to introduce critical elements in their work are often squeezed between student dissonance and structural concerns. Choo (2007) asserted that "the orthodox management curriculum is providing a comfort zone for academic teaching in business schools" (p. 490) for a number of reasons:

- business academics are encouraged to teach skills and competencies rather than addressing cultural complexities

- critical teaching requires small class sizes and labour-intensive teaching methods

- changes in the demands made on academic staff result in reduced time for teachers themselves to practice critical reflection

- critical approaches are considered irrelevant by colleagues

- $\quad$ significantly, governments increasingly require students to be taught specific things, rather than developing as independent thinkers

Choo (2007) stated that the result of this is that "critical management education is a marginalised and selffulfilling activity within higher education, and a major overhaul in the university education system is needed to move the paradigm beyond the language of critique, into practice" (p. 496).

Although there is a powerful case for introducing the "critical" into management education, a number of issues make this problematic, particularly at undergraduate level: increasing staff/student ratios risks limiting the amount of advice and instruction educators can give to students, who require "high touch" levels of guidance when first attempting to shift their learning paradigms; and, students seeking to maximise grades and future employability may not be sold on the demands of developing a critical practice, and revert to learning the system rather than challenging it. Rather than writing these problems off as unmanageable, it is important to consider how the situation might be addressed through initiatives that strive to produce theoretical knowledge, while simultaneously providing practical solutions to issues which show no signs of abating.

\section{The relationship between critical practice and writing skills}

The connection between writing ability and academic performance has been discussed in some detail in the literature (e.g., Graham, Hampton, \& Willett, 2010). The relationship between developing strong selfawareness of one's written submissions and the quality of analytical skills is not new (Locke \& Brazelton, 1997) and much of the theory on critical management pedagogy, which seeks to assist students develop an awareness of the constructed nature of theoretical knowledge and management/organisational realities, demonstrates "how writing can help students to think in critically reflexive ways" (Cunliffe, 2004, p. 411). 
Developing self-awareness in relation to written submissions is an important step in assisting students to develop a mature understanding of their engagement in third-level education as something which should be centred on learning, rather than assessment (Davies, Schulte, \& Johnson, 1995).

The guiding assumption for this investigation was that once students became critical practitioners, their academic writing skills would demonstrably improve in their required coursework. The rationale for this approach was to develop critical thinking practice among students, which would in turn lead to higher standards of academic writing. The approach also called for a deeper level of instructor self-awareness with regards to how the module was actually delivered and assessed. As "we are all prisoners trapped within the perceptual frameworks that determine how we view our experiences" (Brookfield, 1995, p. 28), the assessment of student attempts to write critically runs the risk of becoming skewed by the preferred critical approaches and understanding of the assessor. The design of the course was then informed by, what Cunliffe calls a second-order reflexivity where "we need to be aware of the discursive structures that may subsist in our ways of talking, and how our actions may create and sustain these" (2002, p. 40).

\section{Research design}

During the second semester of the academic year 2009/2010, a 2.5 ECTS credit module titled Critical Writing Skills was delivered: under the European Credit Transfer System model, the course was half the length of usual modules and involved classroom engagement for 1 hour per week, rather than a more standard module teaching engagement of 2 hours per week over 12 weeks. Rather than solely teaching writing skills, the programme was oriented around the development of critical practice amongst students. The assessed outputs from this module were written pieces and exercises designed to encourage students to critically evaluate their own work.

The design developed from the focal research question: how do I encourage a class of 95 first year undergraduate students to engage meaningfully with critical writing practice such that they will be empowered to develop a deeper reflective engagement with the theories they encounter?

In light of the contemporary educational situation, and existing thought on the practical deployment of reflexive and critical thinking amongst undergraduates, the rationale for undertaking this research was to explore the process of engaging a larger class with critical writing skills instruction in order to enhance their independent critical and reflexive capabilities. Lest this appears to be solely a student-centred inquiry, the motivation for undertaking this study had much to do with concerns for the author's own pedagogical practice. At the outset, the following was noted:

I attempt to overcome the lack of engagement from students by trying to make my lectures more engaging - even entertaining! Whereas this appears to work in the classroom settings, I am often surprised (still) at the regurgitation of my course notes in a way that does not demonstrate that students have responsibility for their own studies. So, on the one hand I blame students for not engaging with materials, and on the other, I criticize them for attempting to internalize content. [Personal Journal, January 26, 2010]

These concerns led to the design of the critical writing skills course module and the research strategy to accompany its investigation.

Cresswell (1998) described the design of qualitative research as "the entire process of research from conceptualising a problem to writing the narrative, not simply the methods, such as data collection, analysis and report writing" (pp. 2-3). A detailed account of the learning experiences throughout the process was kept, like Regan-Smith (1996), "both because I did not know a priori what I would find and because I wanted to generate data rich in detail and embedded in context" (p. 127). The research strategy selected was based on the principles of action research as it endeavours "to enter into a situation, attempt to bring about change and to monitor the results" (Hussey \& Hussey, 1997, p. 65). From the beginning of the project, it was necessary for the researcher to become involved in the social learning process that was being initiated and data about the approach adopted throughout the process needed to be collected. In practical terms, this meant that student feedback on the teaching throughout the module was relied on heavily.

Action research carries with it an expectation that is additional to the usual contribution to knowledge required by scholarly inquiry (Remenyi, Williams, Money, \& Swatz, 1998). It also seeks to directly produce practical knowledge that can be validated in action (Gummesson, 1991; Remenyi et al., 1998). The first element was addressed through action research by exploring the issues involved in fostering critical thinking through the development of academic writing skills. The second element sought to address the "how" of adopting this approach through personal critical reflection on the planned teaching approach.

Remenyi et al. (1998) suggested that the action research process should begin with the creation of a static 
picture of the situation and the formulation of a hypothesis based on this. The variables in the picture should then be manipulated by the researcher and the outcomes evaluated with a view to taking a second static picture of the situation. In this project, the process was carried out by creating three main steps or cycles at 4 week intervals. As an action research approach to the question had been chosen, it was important that data could be collected as objectively as the situation allowed, in an effort to avoid reinforcing implicit pedagogical theories through a lens of pseudo-reflexivity. Brookfield (1995) suggested that critical reflection is enabled if we "find some lenses that reflect back to us a stark and differently highlighted picture of who we are and what we do" (pp. 28-29). Critical reflection on our teaching is enabled by four lenses: the teacher's learning autobiography, student perspectives, experiences of colleagues, and theory. The evidential data collected for the project are described below and all attempt, in various ways, to inform the four lenses advocated by Brookfield.

Lesson plans outlining the learning outcomes and activities for each session were developed. Student evaluation forms, which were customised to reflect the content of each session, were issued to all students after every engagement. In particular, students were asked to identify content areas that they were unsure of or were experiencing anxiety about. Student review sessions were held at the end of each 4-week cycle and at the completion of the module all students were invited to attend a final review session. At all of the sessions, participants were encouraged to voice their concerns about any aspect of the module freely. Throughout the action research process, the researcher kept a detailed journal of their experience in the lecture hall. This journal was used to record the teacher/researcher's emotional and intellectual responses to the research initiative as it progressed. As the module represented a new departure, the initiative was discussed with several "critical friends", both inside and outside the researcher's department, and with fellow academics in other institutions.

In order to conduct the widest possible examination of this approach to teaching writing skills through critical engagement, an assessment which was similar in approach was deployed with a group of second year students taking a module in a related but different topic. The rationale for this was two-fold: firstly it sought to test the approach to developing iterative cycles during the same semester but with a different group of learners, in order to contribute a new layer to the evidential data collected. Secondly, it sought to produce results which might be more generalisable and be of greater use to other lecturers grappling with the issue of providing an enhanced learning experience to students in larger classes. Although educational action research is largely qualitative, it is important that researchers working in this mode use every opportunity to see themselves through their students' eyes (Brookfield, 1995). One of the main criticisms levied at this type of classroom action research is that it privileges lecturer knowledge about that of other participants in the research (Kemmis \& McTaggart, 2000). In order to ensure that the project could move beyond the modular climate created within one group who met for 1 hour a week over a 12 week period, data was collected from another group who could similarly inform the process the students were engaged in. All of the methods for collecting data described above were deployed amongst the second year class, who are hereafter referred to as the comparison group.

Although much of the interaction with students was recorded in the personal journal, in order to "cast the net" as wide as possible, copies of all emails and postings to the modules' virtual learning environment (VLE) were kept, across the duration of the project, for possible analysis.

All qualitative information reported in this document is anonymised. In order to produce a craftsman-like report (Watson, 1994), the evidence procured and analysed is discussed at appropriate points in the narrative report section of this paper.

\section{Module design and outline}

Many have engaged with the topic of increasing critical engagement with larger groups of undergraduate students (Abrami et al., 2008; Cutts, 2001; Schermerhorn, Gardner, \& Dresdow, 1992; Wagner \& Van Dyne, 1999). The design of the module was heavily influenced by Cunliffe's (2004) approach to developing critical practice amongst business students which sought to gradually guide students through types of learning as becoming a critical reflexive learner is "very different from the educational experiences of the majority of students" (p. 411). The first type of learning focuses on reflex interaction, which is typical of how individuals instinctively respond to situations which present in everyday life. The second type is reflective analysis, where individuals use theory to make sense and create connections which help them to learn new things about their everyday practice. The final type involves deep explorations of the structures which influence individuals to make sense of the ways in which they create their own realities.

With this in mind, students were asked to complete four assessment exercises throughout the module. Two were short in-class examinations where they were asked to identify errors in citation style or bibliographic apparatuses, uncritical or unsubstantiated statements, incidences of plagiarism, structural or grammatical errors, or informal and colloquial language. One was a short statement of their rationale for self-selecting a 
particular text for analysis. Each of these continuous assessments (CA) accounted for 10\% of the course marks.

The main assessed part of the module was a textual analysis, which accounted for the other $70 \%$ of the marks. Students were asked to produce a critical analysis of a text of their own choosing. This text could be an autobiography or biography of a leader or manager; a personal development text; a text on any management or leadership concept; or a book about work, management, business success or effectiveness.

The rationale for asking students to critically analyse a text about the above topics was to encourage students to closely study how other writers write, and to engage with perspectives which might be critical of their claims. It also asked students to create a well-crafted piece of critical writing, which effectively responded to this text. Course participants were offered the following guidance on self-selecting the material they would analyse:

1. It should be popular, well known or otherwise influential in the public sphere or in management theory.

2. It should be about business, a leader, an aspect of management such as a theory, or a personal development text. Books by well known business leaders offering business advice were eligible for analysis but academic textbooks were not.

3. If students identified a text that did not meet these requirements, but might otherwise be appropriate for review, they were advised to discuss this with the module lecturer before commencing work.

Guidelines were provided to students on how their submissions should be structured and presented, but the main intent of this was to provide signposts for participants who were new to this form of assessment. However, strict penalties for incorrect or inconsistent citations, colloquialisms, unsubstantiated claims, poor bibliographic apparatuses, or other evidence that students had not attempted to produce a quality, wellcrafted piece of writing, were introduced and enforced.

The aim was to design a course which would gradually introduce students to the principles of critical writing practice. Space does not allow for a detailed description of the contents of each section, so an abbreviated outline of each module session with the stated sessional learning outcomes is provided. Additional information on the process of deploying the activities mentioned is provided in the narrative report account of the action research project which follows this section.

\section{Session One: Introduction}

This session introduced the module, its objectives, supporting materials and modes of assessment. A short self-assessment questionnaire was completed which allowed students to consider and report their views on their level of writing skill. The session also outlined the assessment requirements for the module.

Session learning outcome: At the end of this lecture you should have begun to think about a possible text or subject for analysing as part of the main continuous assessment for this module.

\section{Session Two: Critical Practice and Assessment}

The module introduced this session with the following statement: One of the most important elements of becoming a university graduate, is developing an ability to not only think at a deeper level, but to be conscious of how you think about things, and recognise how this may limit your own perspectives and opportunities.

This session demonstrated what critical thinking is by problematising the notion of the "commonsensical", outlining a range of critical approaches which can be brought to management and leadership theory, and highlighting how these might be applied to improve the standard of student writing and coursework. This lecture introduced students to critical approaches which might then be applied to their main continuous assessment exercise for this module. Finally, the session introduced the schedule of assessments for the module.

Session learning outcome: At the end of this lecture you should have further developed a text or subject for critical analysis.

\section{Session Three: Critical Approaches I}

Following Mingers (2000), this session addressed two main forms of critical practice: the critique of rhetorical practices, which is concerned with how language is used; and the critique of conventional wisdom and traditions, which is concerned with how taken-for-granted practices limit our potential for debate or innovation. Demonstrations of each form of critical analysis were provided in class and students were asked to reflect on how these could be applied to their chosen text for analysis. 
Session learning outcome: At the end of this lecture you should have begun to finalise your choice of which text you will analyse for your main continuous assessment and considered which critical approaches you will use in your analysis.

\section{Session Four: Critical Approaches II}

Again, following Mingers (2000), this session explored another two of the central forms of critical practice: the critique of hegemonic practices or authority, which asks why one dominant perspective on any phenomenon tends to prevail and does not allow the accommodation competing viewpoints; and the critique of objectivity of information and knowledge, which demonstrates that theory is never completely value-free or entirely objective. As in the previous session, students were invited to consider how these might be applied to their chosen texts for analysis.

Session learning outcome: At the end of this lecture you should have begun drafting your "Declaration of Topic of Study (Declaration)" for this module's main CA.

\section{Session Five: Assessing Your Own Writing Style}

Students were asked to bring in a printed copy of their draft of their Declaration to the session. Exercises took place in class with other students to: familiarise students with the concept of assessment from the perspective of the assessor, have their own work assessed, and practice assessing another student's work, with a view to developing a deeper understanding of how their own critical writing practice might improve. A template grading sheet was provided to all students to help them consider classmates' work from the perspective of an objective assessor. This was a crucial exercise and all students were urged to engage with it as fully as possible, as they were expected to submit their Declaration within 2 days of this class concluding.

Session learning outcome: At the end of this lecture you should have completed the first draft of your Declaration for this module's main CA, and have began editing the final draft which you will submit.

\section{Session Six: Research, Rigour and Originality}

This session introduced students to the required processes for improving the academic quality of their writing. Using library databases, students were shown how to find relevant theoretical concepts and sources of data relevant to their major assessment project. This session provided the basis for the in-class assessment which would take place in the next session. It also functioned as a feedback stage at the mid-point of the module.

Session learning outcome: At the end of this lecture you should appreciate the concepts of research, rigour, plagiarism and understand how to maximise your usage of library databases.

\section{Session Seven: In-Class Assessment I}

Using the documentation provided for the previous lecture students were given a 40 minute in-class examination where they assessed a short piece of writing (500 words) on the grounds of academic rigour, and also to determine if plagiarism had been committed.

Session learning outcome: At the end of this lecture you will have completed the first in-class CA for the module. All students must attend and no exemptions will be granted.

\section{Session Eight: Feedback Cycle}

Students were asked to bring a copy of their Declaration to the lecture, as generalised feedback was provided to the class on their chosen texts for the major continuous assessment for the module. Theoretical approaches and possible sources were recommended where possible. Students also had the opportunity to raise questions about the assessments to date, and on the module in general.

Session learning outcome: At the end of this lecture you should have a clear understanding of how to advance the development of your continuous assessment.

\section{Session Nine: Citing and Referencing}

Students received specific instruction on how to cite and reference in their academic writing. Specific guidance was provided on how to demonstrate to assessors that participants were using credible research resources. It was envisaged that the fundamentals of this session would provide the basis for the assessment that would take place in the next session.

Session learning outcome: At the end of this lecture you should clearly understand what the rules are regarding citing and referencing in your main CA document. You will also be clear on what you need to know to pass the CA which will run in the following session. 


\section{Session Ten: In-Class Assessment II}

A short in-class examination, which asked students to demonstrate that they understood the formalities of citing written sources and constructing a bibliography, based on the material covered in the previous session, was administered. The material for this assessment comprised a short piece of academic writing which included a bibliography. Students were required to correctly identify ten citation or bibliographic errors in the text.

Session learning outcome: At the end of this lecture you will have completed the second in-class CA for the module. All students must attend and no exemptions will be granted.

\section{Session Eleven: Language, Structure and Grammar}

This session discussed the common pitfalls that students should be aware of when structuring and writing essays. It was of use to the class for two reasons: the deadline for submitting the final draft of the major CA was within 48 hours of this session, which meant that students had an opportunity to review and correct any final errors before submission; the issues discussed were likely to be ones which applied directly to the students in the class on the basis of the Declaration project and other work submitted for assessment.

Session learning outcome: At the end of this session you will have a firm understanding of the grammatical and structural requirements for scoring well in your CA.

\section{Session Twelve: Final Feedback Cycle}

As this course was developed according to the principles of critical action learning, students were invited to raise their concerns about the module and the mode of continuous assessment employed. More importantly, advice for applying critical writing practice to other elements of the degree course and to personal career development plans was offered.

\section{Narrative account of the action research project}

\section{Pre-cycle planning}

To recap, the background to the area of concern was the broader context of management education, which has undergone fundamental changes, and increased calls for the development of students who are both more reflective about the content they encounter and adopt more reflexive approaches to their academic work. Additionally, graduate employers require a greater level of written communication skills in business graduates.

Alongside the emergence of these pressing issues, class sizes in many universities have increased while budgetary cuts have greatly impacted on the higher education sector's ability to recruit new staff to meet increased workload. Existing research on developing critical thinking skills and written communication competencies indicates that these activities are highly labour-intensive, and require a large amount of staff resourcing to be genuinely impactful. When this growing need is compared with a contracting resource base, a situation emerges in which the lecturer is "squeezed". The field of study was thus concerned with the process of teaching critical writing skills to a larger group of students. The literature on critical management education suggests that the amount of labour intensity, lack of student understanding and the lack of assessable criteria had resulted in generally unclear understandings of how to approach the topic. In short, critical thinking skills are difficult to teach and assess. Early in the planning process, the researcher corresponded with an academic outside Ireland who had won an award for critical teaching to business undergraduates, and it became apparent that the issues faced in developing a critical writing skills module were shared.

Most of the activities at the planning stage were driven by a need to clearly communicate to students what they were expected to gain from this process. A detailed module handbook was developed and posted onto the module's VLE, and students were urged to read it before the course commenced. In the introduction to this document, the rationale for the approach taken to the module was articulated. A detailed level of guidance was provided which provided to inform how students should prepare for the course in terms of what they should read, how they would be assessed, and how the module handbook could be used to assist them through the process of developing critical practice.

Perhaps most importantly, students were given an outline of each session, which signposted optional or required reading and a statement of what the student should gain from each session. Just as each session aimed to build on the previous one, the assessments were designed to gradually evaluate student engagement with the key content of the lectures.

\section{Cycle 1: Weeks 1 to 4}

Cycle 1 was designed to introduce and demonstrate to students the key concepts related to critical practice in academic writing. Session one began with an exercise where all students were asked to work in groups to 
provide an answer to the question: What is a graduate? All groups provided answers which demonstrated that they understood a graduate to be someone who had completed a set course of study and acquired a specific stock of knowledge on a particular field, and as result of this was awarded an academic degree. None reported understanding a graduate to be someone who had an advanced ranged of competencies, skills or abilities which could be applied to specific problems or challenges. This was followed with a description of the course rationale, which emphasised the importance of developing a critical practice for future career development, and for success in undergraduate careers.

Critical practice was then demonstrated using the example of a well-known figure from popular culture, the American broadcaster Oprah Winfrey, asking the question: 'Why is Oprah so successful?' The purpose of this exercise was to encourage the development of a critical mindset by persuading students to question their implicitly-held beliefs about a particular subject. With the exception of the only North American student in the class, most reactions were overwhelmingly positive to Winfrey. Some of Peck's (2010) rationale for Winfrey's success (i.e., she provides a set of narcissistic exercises for attaining personal perfection which encourage audiences to accommodate the oppressive impact of neoliberal economic policy, rather than changing it) was then shared. It was noted that this example appeared to work very well, but some students suggested that they felt the course would be "hard". One comparison group student commented that it appeared more involved and demanded a greater level of engagement than was usually expected of students. This was interesting as it may have underlined a degree of disengagement, among certain students, from their learning.

Student evaluations of the introductory sessions for both groups were broadly positive, but there were some notable differences which may be better explained through a qualitative analysis of the comments offered by respondents. As the students found themselves in even larger classes for some of their first semester modules, a small number commented that they preferred the relatively smaller class size of 95 students. Others commented that they enjoyed the approach to teaching writing skills through the encouragement of alternative perspectives.

Although the critical thinking aspect of the course appealed to some, this was not the case for other students:

Don't fully understand how to be critical.

Sounds a bit boring.

Sometimes I don't understand what you mean when you relating stuff back to business [sic].

The final remark above reinforced Mingers (2000) comment that educators and students perceive the rationale for participating in management studies differently: some perceive undertaking a degree in business or management as an opportunity to study management, and some expect that it will teach them how to "do" business or become a manager.

The purpose of the comparison group's module was not to develop writing skills, so they were not asked about this, but it is interesting to note that the first year students awarded themselves poor self-evaluations on their writing skills (an average self-evaluation of 1.88, where the maximum score was 5 ). What this meant became clearer later on in the course. The comparison group gave all aspects of the session higher average evaluations than the core group. The textual comments made on the evaluation forms generally stated that they enjoyed the approach taken to the lectures and the effort taken to engage students.

There were several of these and the researcher recorded feeling very positive about the course from the outset. However, on re-analysing the evaluation forms, it was noticed that students had elected to provide their names on the forms which carried the most laudatory comments. For example, one comment from a control group member stated:

[This was] The first lecture l've thoroughly enjoyed in a long time. Really looking forward to more humorous enthusiastic lectures.

"Power and status differentials fuel ingratiation practices. But they also cause people to censor the expression of their views more generally" (Tourish, 2005, p. 491). Following the first lecture, data on student overall experiences continued to be collected but the researcher was conscious of the need not to be immoderately led by more celebratory comments.

By the time preparation began for the second session, the researcher had begun to feel more apprehensive. In this session, an attempt was made to demonstrate a more thorough example of critical analysis by 
discussing a very popular personal development text which has been re-branded as a management development device (Cullen, 2009). The intention was to very briefly introduce students to a popular text and then critically analyse it, with the intention of demonstrating how this practice might be done. This would provide the bedrock for the next two lectures which aimed to take students deeper inside the process of becoming critical.

The comparison group expressed a general opinion that they would understand the concept of becoming critical as the course progressed:

As time goes on I'm sure l'll get a better understanding of the overall course.

Hopefully with a lot of reading it should be ok

Not sure but still have a good idea.

Although not obvious at the time, this tentative engagement proved salient and is returned to later. Other comments indicated that the students had never encountered an assessment like this before, and that they would like to have more examples of continuous assessments.

It would be good to know how exactly to approach analyzing a text for the CA [continuous assessment].

The way in which to set about starting a critique.

There was concern about this line of inquiry: critical thinking involves independently researching a topic of one's choosing and not following a set formula. However, it was appreciated that this was a novel form of assessment for students.

Part of the assignment involved students self-selecting texts for analysis. Due to the lack of certainty about which type of text they should choose, a draft list of possible texts to analyse was developed. At the start of the third session, students were asked how they had progressed with this selection. The personal journal contains the researcher's reaction following the session:

Many of the students, however, had not thought about their text for analysis and I would say a good $1 / 3$ had not read the CA outline. Disappointing. I ran out of time and could not deliver my reading for the piece so I really need a good example to help explain this to them. Also, I wonder if I've pitched this too high for them. The vast majority appeared to simply pick a book from the list I provided. How can I get students interested in theory?

At this stage, it was important to consider that students had been given ample support and documentation which outlined the requirements of the course. If many students had not ventured to download these and participate in the exercises that had been set, how much credence should be placed on data solicited in evaluation forms? This mild sense of frustration would later provide an insight into expectations as the course teacher.

Following Mingers' (2000) framework, session three and four of the first cycle attempted to share some broad critical approaches with students: session three focused on rhetorical critiques and critiques of traditional wisdom, and session four focused the critique of hegemony, authority and the objectivity of information.

The main thrust of the comments collected from these sessions was that students were unclear about how to proceed with their critical analyses. This was addressed by providing an in-class critical analysis of a short piece of text from Rich Dad, Poor Dad (Kiyosaki \& Lechter, 1998) a popular financial self-help text. Student's appeared to respond well to this, which may account for the increase in student ratings of the next session. Much time was spent in the class discussing one particular student's choice, Who Moved My Cheese? (Johnson, 1998). The evaluation forms indicated that, at the end of this session, 55 of the 61 students who attended the class had selected a text for analysis which was a marked improvement on the previous week's results. However, 15 of these stated that they would study Who Moved My Cheese?, which perhaps demonstrates that the discussion in the session provided some students who had not engaged up to that point with a framework and a structure to progress their analyses. Those students who engaged in the discussion pointed out that it was a brief text, was simplistic and did not require a significant level of engagement, and this may have influenced some less engaged students to select it.

Throughout all of the sessions, an active attempt was made to engage students and they were encouraged to discuss their texts for analysis openly, but many of the traditional pre-experience students appeared to be very reticent when compared with international or mature students. This led to a number of questions being 
directed to the researcher via the VLE, email or in their office, about the appropriateness of their declared texts for analysis, which frequently did not appear to have been considered very well. Growing frustration about this was noted:

Just had another student in with a totally inappropriate text for analysis. [The student] hadn't downloaded anything (Continuous Assessment description or my list for potential texts to review). There appears to be a lot of stampeding without thinking. Why is this happening?

That said, the ones who "get it", appear to really get it. Is my job to let the ones who are not putting the energy into this, sink? What are my responsibilities here? What are my duties? I've become irritated by the poor performers and have let them distract me from the diligent students. [Personal Journal, February 25, 2010]

At the end of this cycle, a working theory was developing about the students in the class: some were engaged with the process and wanted to learn; others were disengaged and expected to be told what to do. Soon after the completion of this cycle, the researcher experienced something of an epiphany with regard to the pedadogical approach. Teaching critical skills should not aspire to creating a teleological position; rather it is a process which requires guidance and development. Rather than assuming that the focal research question had been answered in the negative, the next stage of the cycle was begun, seeking to improve on the results so far.

\section{Cycle 2: Weeks 5 to 8}

The activities of the first introductory session were designed to provide the bedrock to the first assessment, where students were asked to deliver a copy of their Declaration. Students were expected to bring a draft copy of their assessment to the lecture, with a view to sharing their approach with other students and assessing other students work on the basis of the criteria set for them. The average mark received for the first assessment was $56.5 \%$. In keeping with the spirit of the research question, detailed feedback was provided, on the VLE and in class, on how these assignments might be improved in the following areas:

- application of critique

- rigour

- presentation

- writing style

This was built on by introducing students to the concepts of rigour and originality in developing a critical analysis, with a strong emphasis on using quality information sources to support their final textual critiques. This was assessed via a short in-class examination in session seven, which explored these concepts by asking students to assess a short piece of writing on the grounds of its academic rigour and also to determine if plagiarism was committed. As this assessment explicitly built on initial feedback, there was a somewhat encouraging (if slight) increase in grades, with the class average moving up to $60 \%$. The final session in this cycle was a feedback session where students would effectively set the content. Students generally stated that they felt the module was interesting and had grasped the more technical elements well (such as plagiarism, research strategies, etc.), but many expressed continuing unease about how to approach their critical analyses. The researcher "kept the touch 'light' - I don't want to be too prescriptive [about how to be critical] bearing in mind they're still first years and are only beginning to engage in the process." [Personal Journal, March 29, 2010]

\section{Cycle 3: Weeks 9 to 12}

By the start of the third session, several students commented that penalties for writing errors in the major assessment were quite severe. Session nine outlined specific instructions for how to cite and reference, and this provided the basis for the in-class assessment in session ten, where students were asked to correctly identify ten writing errors in a piece of academic writing. The rationale for this, like the first in-class assessment which ran in session seven, was to get students to critically distance themselves from their own work and see it from the perspective of the assessor. Results again were in median range, with a $54 \%$ average for the class, but many students began to report that the import of writing well was beginning to dawn on them and some reflected that they had wished they had attended more of the earlier sessions. The earlier written assessment submitted by the students was used as a focus to discuss the major structural and grammatical pitfalls that the class risked when developing their final assessment. The assessment had to be submitted within two days of this session and it was anticipated that it would have been a little more mundane than usual, but student engagement was very strong in the session.

Didn't expect yesterday's session to go as well as I thought. Real reason was that I think it really emphasized to students the necessity of being conscious of how they write. Feeling a little bit of a breakthrough here. Felt that it really impacted the group and they got it. [Personal Journal, April 27, 2008] 
This was reflected in the major continuous assessment for the course, where the average grade rose by another two per cent to 58\%, and 22 students (of 95) achieved a first class honour for their final assessment, which demonstrated that they had conducted a solid critical analysis written at a graduate level. Some of the critiques were exceptionally rigourous and this was genuinely surprising. Perhaps most remarkable was the increase in grades as the module increased. The majority of students who received first class honours or $2.1 \mathrm{~s}$ demonstrated an increase in their grades across each assessment element, which perhaps indicates a growing level of engagement throughout the process.

The vast majority of students who failed did so as a result of not submitting assessments. The final scheduled session took place after the submission date for the major continuous assessment so a small turnout for review was anticipated. Three short sessions were scheduled to solicit final student feedback. In all, 19 students attended and their overall evaluation scores reflected a high level of understanding of what it meant to be critical, and the role of writing in helping students become critical.

One student, very honestly, reported that she hated the course and did not see the point of it, but this was not the general experience. Most students reported that they had learned a great deal, particularly the importance of using writing to demonstrate a critical mindset in future assignments. However, several sought more examples of solid critical writing to help them address feelings of uncertainty that they had about their work. Two felt that the amount of work required for a 2.5 credit module was too much, but an international student said that there should have been more work attached to the module. Another student stated that it had fundamentally impacted on how she thought about things in general:

I find in my personal life I am critically assessing random books and television shows. Looking past the common ideas or face value.

\section{Findings and conclusions}

This action research project started with the aim of answering the question: how do I encourage a class of 95 first year undergraduate students to engage meaningfully with critical writing practice such that they will be empowered to develop a deeper reflective engagement with the theories they encounter? The work undertaken highlighted a fundamental presumption within the question, namely that the larger class size itself the main problem. Rather it is the diversity of expectations within a larger class that is a problem. Some students were willing to take responsibility for their own development from the outset and sought out a meaningful learning experience, but others had not taken this on and failed to complete tasks that were designed to help them achieve better grades in general. Hopefully this was addressed across the progress of the module, but further research is required to see how this might impact in the participating students' future undergraduate careers. A key insight that emerged following the completion of the data collection stage is that there is also a diversity of approaches which could be taken to address this issue in large introductory classes, which include the structural design of modules (Wagner \& Van Dyne, 1999) and the use of blended learning approaches (Moore \& Gilmartin, 2010).

The implications for the future teaching of a module according to the approach described in this article are as follows:

1. The results for the course demonstrate that there is strong correlation between the quality of writing and the rigour applied to critical analysis. However, this is based on a very small sample size and requires more extensive data collection in the future.

2. Although stated from the outset that the module was additive, stronger emphasis needs to be placed on the fact that students who engaged early and understood the principle of critical thinking performed better overall in their assessments.

3. Although students should not be told how to do a critical analysis, they think that they need to see examples of this to do well. These were provided as optional reading from the outset, in the module handbook, and short demonstrations were given in class. It only became clear at the end of the module that the participants sought examples of other students' work.

4. Engagement with the topic under investigation is the first step to developing a critical approach to it. Students were asked to focus on texts but other non-media based approaches, such as critical presentations or debates, might work just as well (Warhurst, 2001).

5. Developing a critical writing practice is a process, and it takes an entire course to properly introduce students to the concept of critical writing/thinking in a way that they only really appreciate at the end. This could be applied in contexts outside a specific critical writing skills course. 
6. Students are primarily concerned about grades. The application of strict penalties to the major critical writing assessment, and demonstrating to students the consequences of not following these, were perhaps the most impactful elements of the module. Some students achieved real learning and a broadening of horizons as a result of the course, but most who responded stated that they felt it would be of most benefit to their future writing assignments.

The positive experiences ranged from the emancipatory to the instrumental, and it was only towards the end of the project that this was recognised and what had been expected from the students on the course was questioned. Either are gateways into the beginning of the process of becoming critical.

Students "jump through hoops" set for them in order to get the needed qualification. The emphasis is on memorisation and reproduction. (McMahon, 1999, p. 165)

Sometimes students need these hoops. For example, understanding the importance of citing correctly can lead to an understanding of why certain sources are valid and credible, and demonstrate the difference between theory, data and opinion. Linking the development of writing skills with the process of developing a critical mindset has strong potential appeal at an instrumental level that students clearly understand as "poor writing ability impairs employability as well as academic potential" (Graham et al., 2010, p. 68). More importantly, it is also has the potential to introduce students to the process of understanding the theories and declarations of others in a way which is deep and intellectually engaged, and start them on the path to becoming critical.

Finally, to return to the concerns which led to the inception of this research; anxieties about the quality of writing and critical skills amongst undergraduate students are often raised in isolation of each other and tend not to be discussed as if they do not stem from the same set of circumstances, but these findings suggest that this relationship may be more synchronous. This research was led by the assumption that once students genuinely developed their critical practice that their academic writing skills would improve. The question of whether the inverse is true (i.e., that effective written communication drives the ability to thinking clearly and critically) presents both a research need and an opportunity to deliver a module similar to the one described here, but from a different point of departure.

A key selling point for linking critical thinking and writing stills for students is that learning how to communicate effectively and professionally in writing aids their ability to think clearly and critically. This in turn impacts on their grades and potential to succeed in the recruitment market and in business. Insisting on high standards of writing from our students in all subject areas, and penalising instances where written performance has been sub-optimal, is a way of aligning assessment with the process of learning. Clear guidelines for what is desirable in submitted written work, and for what will be penalised, is a useful approach for assisting the assessment process where class sizes are larger, but it is crucial to allow students to practice this in groups or independently before delivering course work. Doing so carries with it the possibility of reducing the diversity of expectations issue which emerges from large class scenarios mentioned in this paper, without imposing strictures which limit creative and critical abilities.

Ultimately, the development of critical practice involves the students owning responsibility for engagement with the material they encounter and responding to this through their writing. This is not impossible in larger class sizes and the development of this mindset can be encouraged through faculty resourcing students to engage with this principle in the design of assessments.

\section{Acknowledgement}

The author would like to thank the reviewers of this paper for their input and encouragement.

\section{References}

Abrami, P. C., Bernard, R. M., Borokhovski, E., Wade, A., Surkes, M. A., Tamim, R., \& Dai, Z. (2008). Instructional interventions affecting critical thinking skills and dispositions: A stage 1 meta-analysis. Review of Educational Research, 78, 1102-1134. doi:10.3102/0034654308326084

Bennis, W. G., \& O'Toole, J. (2005). How business schools lost their way. Harvard Business Review, 83(5), 96-104.

Brookfield, S. (1995). Becoming a critically reflective teacher. San Francisco, CA: Jossey-Bass.

Choo, K. L. (2007). Can critical management education be critical in a formal higher educational setting? Teaching in Higher Education, 12, 485-497. doi:10.1080/13562510701415524

Creswell, J. W. (1998). Qualitative inquiry and research design: Choosing among five traditions. Thousand Oaks, CA: Sage Publications.

Cullen, J. G. (2009). How to sell your soul and still get into heaven: Steven Covey's epiphany-inducing technology of effective selfhood. Human Relations, 62, 1231-1254. doi:10.1177/0018726709334493 
Cunliffe, A. L. (2002). Reflexive dialogical practice in management learning. Management Learning, 33 , 35-61. doi:10.1177/1350507602331002

Cunliffe, A. L. (2004). On becoming a critically reflexive practitioner. Journal of Management Education, 28, 407-426. doi:10.1177/1052562904264440

Cutts, Q. (2001). Engaging a large first-year class. In M. Walker (Ed.), Reconstructing professionalism in university teaching: Teachers and learners in action (pp. 105-128). Buckingham, England: SRHE \& Open University Press.

Davies, W., Schulte, M. F., \& Johnson, V. E. (1995). Two-draft term papers: Improving the pedagogical value of written assignments. Journal of Management Education, 19, 250-253. doi:10.1177/105256299501900210

Dehler, G. E. (2009). Prospects and possibilities of critical management education: Critical beings and a pedagogy of critical action. Management Learning, 40, 31-49. doi:10.1177/1350507608099312

Ferlie, E., McGivern, G., \& De Moraes, A. (2010). Developing a public interest school of management. British Journal of Management, 21, s60-s70. doi:10.1111/j.1467-8551.2009.00681.x

Flynn, S. (2010, August 23). "Points race" back as CAO offers show rise in entry standards. The Irish Times, p. 1.

Ghoshal, S. (2005). Bad management theories are destroying good management practices. Academy of Management Learning \& Education, 4, 75-91. doi:10.5465/AMLE.2005.16132558

Graham, A., Hampton, M., \& Willett, C. (2010). What not to write: An intervention in written communication skills for accounting students. International Journal of Management Education, 8(2), 67-74. doi:10.3794/ijme.82.265

Grey, C., \& Willmott, H. (2005). Critical management studies: A reader. Oxford, England: Oxford University Press.

Gummesson, E. (1991). Qualitative methods in management research. Newbury Park, CA: Sage Publications.

Hagen, R., Miller, S., \& Johnson, M. (2003). The "disruptive consequences" of introducing a critical management perspective onto an MBA Programme. Management Learning, 34, 241-257. doi:10.1177/1350507603034002005

Hussey, J., \& Hussey, R. (1997). Business research: A practical guide for undergraduate and postgraduate students. Basingstoke, England: Palgrave.

Johnson, S. (1998). Who moved my cheese? An amazing way to deal with change in your work and in your life. New York: Putnam.

Kemmis, S., \& McTaggart, R. (2000). Participatory action research. In N. K. Denzin \& Y. S. Lincoln (Eds.), Handbook of qualitative research (pp. 567-605). Thousand Oaks, CA: Sage.

Kiyosaki, R. T., \& Lechter, S. L. (1998). Rich dad, poor dad: What the rich teach their kids about money - that the poor and middle class do not! Paradise Valley, AZ: TechPress.

Locke, K., \& Brazelton, J. K. (1997). Why do we ask them to write, or whose writing is it, anyway? Journal of Management Education, 21, 44-57. doi:10.1177/105256299702100104

Martin, R. (2010, January 11). MBA world needs to broaden its horizons. Financial Times, p. 1.

McMahon, T. (1999). Is reflective practice synonymous with action research? Educational Action Research, 7 , 163-169. doi:10.1080/09650799900200080

Mingers, J. (2000). What is it to be critical? Teaching a critical approach to management undergraduates. Management Learning, 31, 219-237. doi:10.1177/1350507600312005

Mintzberg, H. (2004). Managers not MBAs: A hard look at the soft practice of managing and management eevelopment. New Jersey: Pearson Education.

Moore, N. , \& Gilmartin, M. (2010). Teaching for better learning: A blended learning pilot project with first-year geography undergraduates. Journal of Geography in Higher Education, 34, 327-344. doi:10.1080/03098265.2010.501552

Newman, M. (2010, January 10). The bottom line is not enough: How business schools fail their students. Times Higher Education Supplement. Retrieved June 18, 2010, from http: / / www.timeshighereducation.co.uk/story. asp?storycode $=409826$

Peck, J. (2010). The secret of her success: Oprah Winfrey and the seductions of self-transformation. Journal of Communication Inquiry, 34, 7-14. doi:10.1177/0196859909351145

Raelin, J. A. (2007). Toward an epistemology of practice. Academy of Management Learning \& Education, 6, 495-519. doi:10.5465/AMLE.2007.27694950

Regan-Smith, M. G. (1996). How basic science teachers help medical students learn: The student's perspective. In J. A. Maxwell (Ed.), Qualitative research design: An interactive approach (pp. 117-137). Thousand Oaks, CA: Sage.

Remenyi, D., Williams, B., Money, A., \& Swatz, E. (1998). Doing research in business and management: An introduction to process and method. London: Sage.

Schermerhorn, J. R., Jr., Gardner, W., L. III, \& Dresdow, S. A. (1992). Success profiles for student examination performance in a large-lecture management course: An empirical study. Journal of Management Education, 16, 430-443. doi:10.1177/105256299201600403

Tourish, D. (2005). Critical upward communication: Ten commandments for improving strategy and decision making. Long Range Planning, 38, 485-503. doi:10.1016/j.lrp.2005.05.001

Usher, A., \& Cervenan, A. (2005). Global higher education rankings 2005: Affordability and accessibility in comparative perspective. Toronto, Canada: Educational Policy Institute. 
Valentin, C. (2003). How can I teach critical management in this place? Contradictions and compromise on a multi-cultural masters programme in HRD: A study of work in progress. Paper presented at the Critical Management Studies Conference, Lancaster University. Retrieved June 18, 2010, http://www.mngt.waikato.ac.nz/ejrot/cmsconference/2003/proceedings/criticalturn/Valentin.pdf Vince, R. (2010). Anxiety, politics and critical management education. British Journal of Management, 21(Suppl. 1), s26-s39. doi:10.1111/j.1467-8551.2009.00678.x

Wagner, J. A., III, \& Van Dyne, L. (1999). The large introductory class as an exercise in organization design. Journal of Management Education, 23, 123-142. doi:10.1177/105256299902300203

Warhurst, C. (2001). Using debates in developing students' critical thinking. In M. Walker (Ed.), Reconstructing professionalism in university teaching: Teachers and learners in action (pp. 81-104). Buckingham, England: SRHE \& Open University Press.

Watson, T. J. (1994). Managing, crafting and researching: Words, skill and imagination in shaping management research. British Journal of Management, 5(Suppl. 1), s77-s87. doi:10.1111/j.1467-8551.1994.tb00132.x

Williams, R., \& Shepherd, J. (2010, August 24). GCSE results: University crisis to hit school students, union warns. The Guardian, p. 1. 